\title{
ESA economies may allow Mars mission
}

[MUNICH] The European Space Agency (ESA) is drawing up plans for a quick, lowcost mission to Mars as a way of partly restoring the frequency of research missions, which are under heavy pressure from falling budgets.

ESA's Space Science Advisory Committee discussed the plan for the Mars Express mission last week. But Lodewijk Woltjer, the head of the committee, warns that the mission will be possible only if the agency's member states do not impose further financial restrictions on the space science programme.

The committee of eight European space scientists had been asked to redesign. ESA's long-term Horizons 2000 plan in the light of the programme's reduced financial projections. Horizons 2000 is a mixture of large cornerstone missions and medium-sized missions designed to balance the needs of Europe's space science community.

In January, the committee proposed stretching out the programme. But this suggestion came under criticism from some member states because delaying launches would disrupt the flow of data to European scientists in a way that they found unacceptable (see Nature 386, 421; 1997).

Following a series of studies into ways of saving costs, the committee is now proposing that two planned missions should be launched together in 2005 or 2006 - the cornerstone Far Infrared Telescope, and the medium-sized Planck Surveyor, which will study microwave emission from the sky. By sharing the launch, the spacecraft and the high-technology cooling system, ESA expects to save ECU300 million (US\$340 million), without significantly delaying either mission.

The committee is proposing that half of the sum saved should help to pay for the relaunch of Cluster, the solar science mission that was destroyed when its Ariane 5 launcher exploded last year. The other half, it says, should be reserved for the Mars mission.

The committee says the costs of Mars Express can be kept down to around ECU150 million by using blueprints of instruments designed for other missions but never used. These instruments, including some of those lost on the Russian Mars 96 mission when its Proton launcher failed last November (see Nature 384, 199; 1996), would allow some fundamental scientific experiments to be carried out, such as unique spectral analysis of the surface of Mars.

Woltjer stresses that there are two reasons why the proposed 2003 launch date must be kept to if the mission is to stay within its budget. First, the positioning of planets during that year will leave a clear path to Mars, minimizing the fuel required. Second, the scientific relevance of the instruments could be reduced after this date by the continuing Mars exploration programme.

The committee is also proposing a significant future participation in the Next Generation Space Telescope, the follow-up to the Hubble Space Telescope.

The cost-saving analyses by ESA have been unable to identify how to bring forward the next unallocated medium-sized mission, which remains delayed until 2007. Nor could the agency fix a date for the next cornerstone mission, originally due to be launched in 2009. This was intended to be an interplanetary mission to Mercury but the committee is now to reconsider its aim.

A series of cheap technology testing missions, SMART (Small Missions for Advanced Research in Technology), is expected to get off the ground. Officials propose that the first, to demonstrate the feasibility of solar electric propulsion as a way of reducing fuel requirements for interplanetary missions, should be launched to the Moon in 2002. Alison Abbott

\section{US science adviser's exit 'may herald new White House strategy'}

[WASHINGTON] Jack Gibbons, science adviser to President Bill Clinton, has countered growing speculation about his future in the post in a statement saying that he is staying put - but "may desire to leave near the end of the year".

Gibbons issued the statement in response to reports that John Deutch of the

Massachusetts Institute of Technology was in line to replace Gibbons this summer. Deutch has held various senior posts in a series of recent administrations, mostly recently as director of the Central Intelligence Agency (CIA).

The vague statement has left science lobbyists in Washington concerned that uncertainty about Gibbons' future could undermine the influence of the Office of Science and Technology Policy (OSTP), which he runs in the White House.

But well-placed sources say that the statement points to Gibbons presiding over a transition period before making way, probably at the beginning of next year, for a new adviser who, it is said, will increase the profile of science and technology issues at the White House.

Administration officials and Deutch have declined to confirm or deny that he will be that person - fuelling speculation that he is the front-runner. The statement said: "Dr

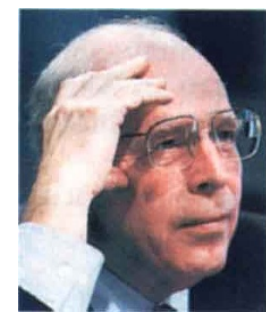

John Gibbons continues to serve as the director of OSTP, and continues to advise the president. Any contemplation about his successor is premature speculation. Dr Gibbons has Gibbons: doubts over indicated that he may his effectiveness. desire to leave this post near the end of the year. When that time comes, a number of leaders in the US science and technology community will be considered for this critical position."

Reports of a Deutch appointment surfaced as science advocates expressed growing concern about the lack of a clear statement about Gibbons' intentions, as well as doubts about his effectiveness in Washington's corridors of power. One senior physicist said privately last week that Gibbons was "not a player" in Washington. And an official in a major scientific society said OSTP was "adrift", having "a director whom everyone says is going to leave".

After the statement, science lobbyists said that it might make things even worse. If a successor is not in place until 1998, they said, that person will have little time to accomplish anything before the second Clinton term, which ends in 2000 , enters the "lame duck" phase which besets most presidents in their final 18 months in office.

Gibbons refused to expand on his statement, or to comment on reports that OSTP's influence in the White House was being usurped by John Podesta, Clinton's deputy chief of staff and a former lobbyist for high-technology corporations. According to the newsletter Washington Fax, Podesta wants the administration to restore the strong emphasis on technology support that Clinton promised early in his first term.

The Deutch rumour puzzled officials in the Congress. They say that Deutch left the CIA job on bad terms with Clinton, after he had failed to land the job he wanted as secretary of defence. They point out that the science adviser's job, as traditionally defined, is junior to both of these positions.

But the appointment of a high-profile adviser such as Deutch could fit in with a long-term White House science policy strategy. This was outlined by one official, who said that Gibbons could be a "transitional figure" from that of a traditional science adviser to one under which science would become a "major policy area". Such a move would place concern for research on a par with economics or national security.

coin Macilwa'n 